\title{
Fractura de Tillaux
}

\author{
Tillaux fracture
}

\author{
René Ochoa Cázares, ${ }^{*}$ José Antonio Chávez Sevilla, ${ }^{\ddagger}$ Daniel Arturo Valdez Toval ${ }^{\ddagger}$
}

Citar como: Ochoa CR, Chávez SJA, Valdez TDA. Fractura de Tillaux. Acta Med GA. 2021; 19 (4): 547-549. https://dx.doi.org/10.35366/102544

\section{Resumen}

La fractura de Tillaux es un tipo de fractura de presentación poco común, muchas veces pasa inadvertida como un simple esguince de tobillo. Tiene implicaciones serias que llevan a la inestabilidad de la articulación tibioastragalina que podría desencadenar en artrosis temprana. La literatura disponible evidencia alta tasa de consolidación ósea y pocas complicaciones. Se presenta en pocas oportunidades el cierre prematuro fisiario debido a que la fisis se encuentra casi cerrada. Presentamos reporte de caso de un paciente adolescente quien sufrió fractura aislada de Tillaux. El paciente fue intervenido quirúrgicamente, se le practicó reducción abierta y fijación interna definitiva con el objetivo de establecer la congruencia articular tibioastragalina.

Palabras clave: Fractura de Tillaux, esguince de tobillo, periodo de transición, cierre prematuro fisiario.

\section{INTRODUCCIÓN}

El cierre epifisario de la tibia distal tiene un patrón asimétrico, el cierre fisario inicia en el centro y luego progresa hacia el lado medial, finalmente se produce la fusión del aspecto lateral de la tibia distal. El cierre medio ocurre aproximadamente a los 13-14 años de edad, el cierre lateral inicia entre los 14.5 y 16 años de edad. El intervalo (aproximadamente 18 meses) durante el cual la fisis tibial distal completa su cierre y gana madurez, es referido como el "periodo de transición". La fractura de Tillaux en la adolescencia ocurre durante el periodo de transición

\section{Abstract}

Tillaux fracture is a type of fracture with a rare presentation, many times it goes unnoticed as a simple sprain and has serious implications that lead to instability of the tibiotalar joint that could lead to early osteoarthritis. The available literature shows a high rate union of the same and few complications as well as no physeal premature closure because it is a type of fracture where the entire physis is almost completely closed. We present a case report of an adolescent patient who suffered an isolated Tillaux fracture. The patient underwent surgery, performing open reduction and definitive internal fixation, with the objective of establishing articular congruence of the tibiostragalina.

Keywords: Tillaux fracture, ankle sprain, transition period, physeal premature closure.

cuando la fisis medial y central ha terminado el cierre, pero la fisis lateral aún está abierta. Los ligamentos son más fuertes que el hueso en la adolescencia, por lo que el hueso fallará antes que los ligamentos. La fractura de Tillaux está clasificada como una Salter Harris tipo III, o fractura de la epífisis porque el platillo de crecimiento de la tibia distal lateral aún está abierto. ${ }^{1}$

Tillaux llevó a cabo experimentos cadavéricos y descubrió que la fractura de la tibia distal es debida a la tracción del ligamento tibioperoneo anteroinferior, este patrón de fractura fue conocido como fractura de Tillaux en adultos y fractura juvenil de Tillaux en adolescentes. ${ }^{2}$
* Director del Curso Artroscopia y Reconstrucción Articular. Hospital Angeles Pedregal, Facultad Mexicana de Medicina Universidad La Salle Campus México.

₹ Fellow en Artroscopia y Reconstrucción Articular. Hospital Angeles Pedregal, Facultad Mexicana de Medicina Universidad La Salle Campus México.

\section{Correspondencia:}

Dr. René Ochoa Cázares

Correo electrónico: roc.ortopedia@gmail.com

Aceptado: 10-12-2020.

www.medigraphic.com/actamedica 


\section{PRESENTACIÓN DEL CASO}

Paciente masculino adolescente de 15 años de edad, quien acude a sala de urgencias con historia de trauma a nivel del tobillo derecho que causa dolor agudo e incapacitante para el apoyo y la marcha.

A consecuencia del trauma, el paciente presenta dolor con escala de EVA de 9/10, limitación funcional, tumefacción y equimosis del tobillo principalmente en la cara anterolateral de la articulación.

Se realizaron radiografías simples de tobillo (anteroposterior y lateral) y del pie (anteroposterior, lateral y oblicua), las cuales evidenciaron fractura de la porción distal de la tibia derecha, justo en la cara anterolateral, con trazo articular al tobillo y presentando escalón articular mayor de 2 $\mathrm{mm}$. Se clasifica lesión ósea como fractura Salter y Harris tipo III/fractura de Tillaux (Figura 1 A y B).

\section{Técnica quirúrgica}

Paciente masculino que fue llevado a sala de operaciones bajo anestesia regional con bloqueo espinal. Se coloca isquemia en el tercio proximal al muslo derecho, se realiza abordaje anterolateral de tobillo derecho, y se diseca por planos respetando las estructuras anatómicas, siendo gentil con los tejidos blandos.

Se visualiza fragmento óseo inestable, pero fácilmente reductible, con ayuda de clavillo Kirschner se realiza fijación temporal del fragmento óseo (técnica de Joystick) y se coloca tornillo canulado de $3.5 \mathrm{~mm}$ de rosca parcial más arandela de lateral a medial y paralelo a la línea articular.
Se observa directamente reducción satisfactoria y adecuada congruencia articular, por medio de fluoroscopia se cierra por planos los tejidos blandos, colocando férula con tobillo en $90^{\circ}$.

Al cabo de 10 días de la cirugía se retiran los puntos de la piel, se coloca aparato de yeso podálico de fibra de vidrio por cuatro semanas.

A las 10 semanas el paciente presenta marcha con apoyo total. Se establece evolución satisfactoria en el seguimiento según las escalas de Foot and Ankle Ability Measures de $97 \%$, escala visual análoga de dolor de 0/10, AOFAS de 100 y SF-36 de 98.00 (Figura 2 A y B).

\section{DISCUSIÓN}

Los fragmentos de la fractura de Tillaux-Chaput son pequeños y resultan en leve edema, deformidad y obstrucción del peroné, con lo que estas fracturas tienden a no ser diagnosticadas y pasar inadvertidas como un simple esguince de tobillo. La fractura de Tillaux es una típica fractura intraarticular, así que cuando el fragmento desplazado presenta escalón articular y es mayor de $2 \mathrm{~mm}$, el paciente requiere reducción abierta y fijación interna.

Este tipo de trauma es tratado usando una incisión tibial anterolateral, la reducción se logra por lo regular con uno o dos tornillos de compresión. ${ }^{3,4}$

Tornillos canulados y alambres de Kirschner empleados en la fijación después de la reducción cerrada son útiles para fracturas epifisarias del maléolo lateral y medial en niños, los resultados confirmaron una alta tasa de unión y respuesta satisfactoria funcional sin complicaciones. ${ }^{5}$ Por la
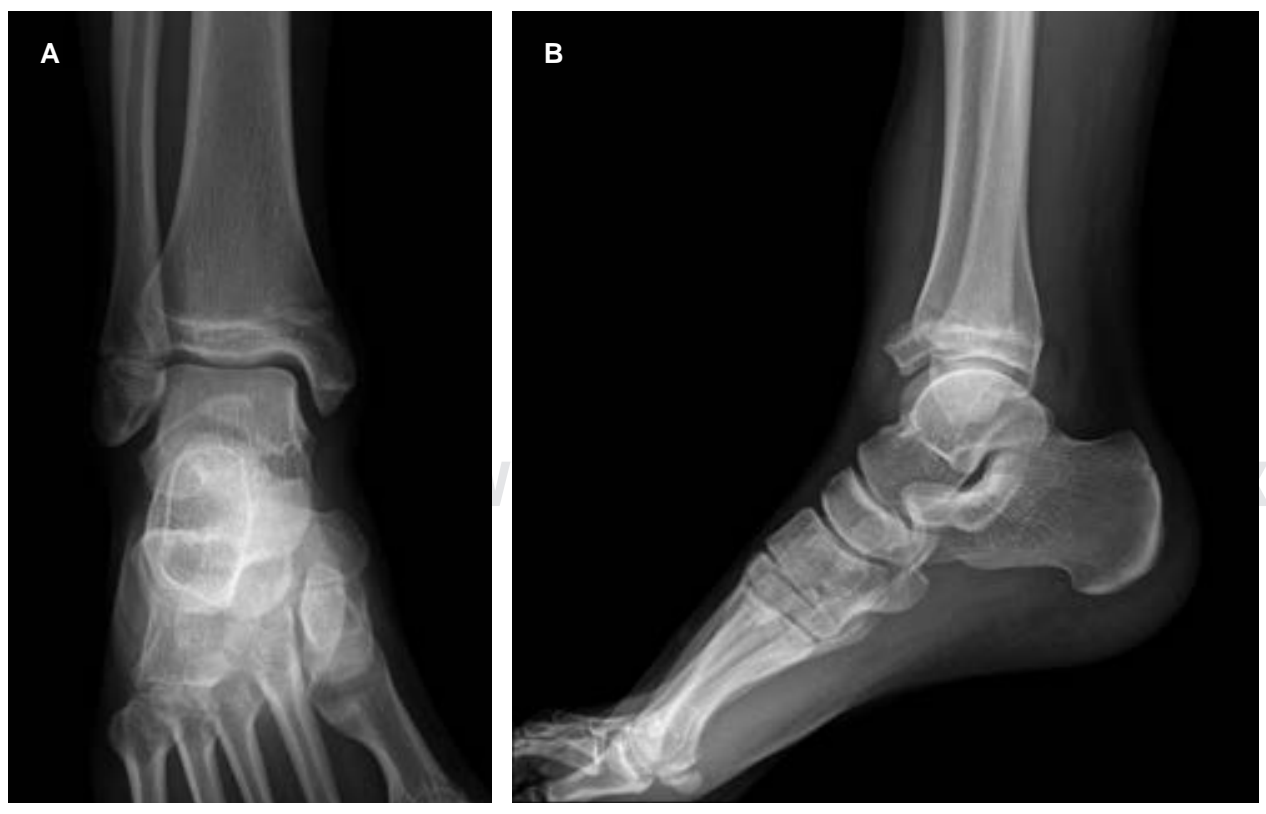

Figura 1:

A y B) Proyección radiológica anteroposterior y lateral del paciente a su ingreso en sala de urgencias. Fuente: Foto archivo Dr. René Ochoa Cázares. 
Figura 2:

A y B) Proyección radiológica anteroposterior y lateral del tobillo derecho a las cuatro semanas postquirúrgicas, observándose adecuada reducción y colocación del implante para la fijación ósea. Fuente: Foto archivo Dr. René Ochoa Cázares.
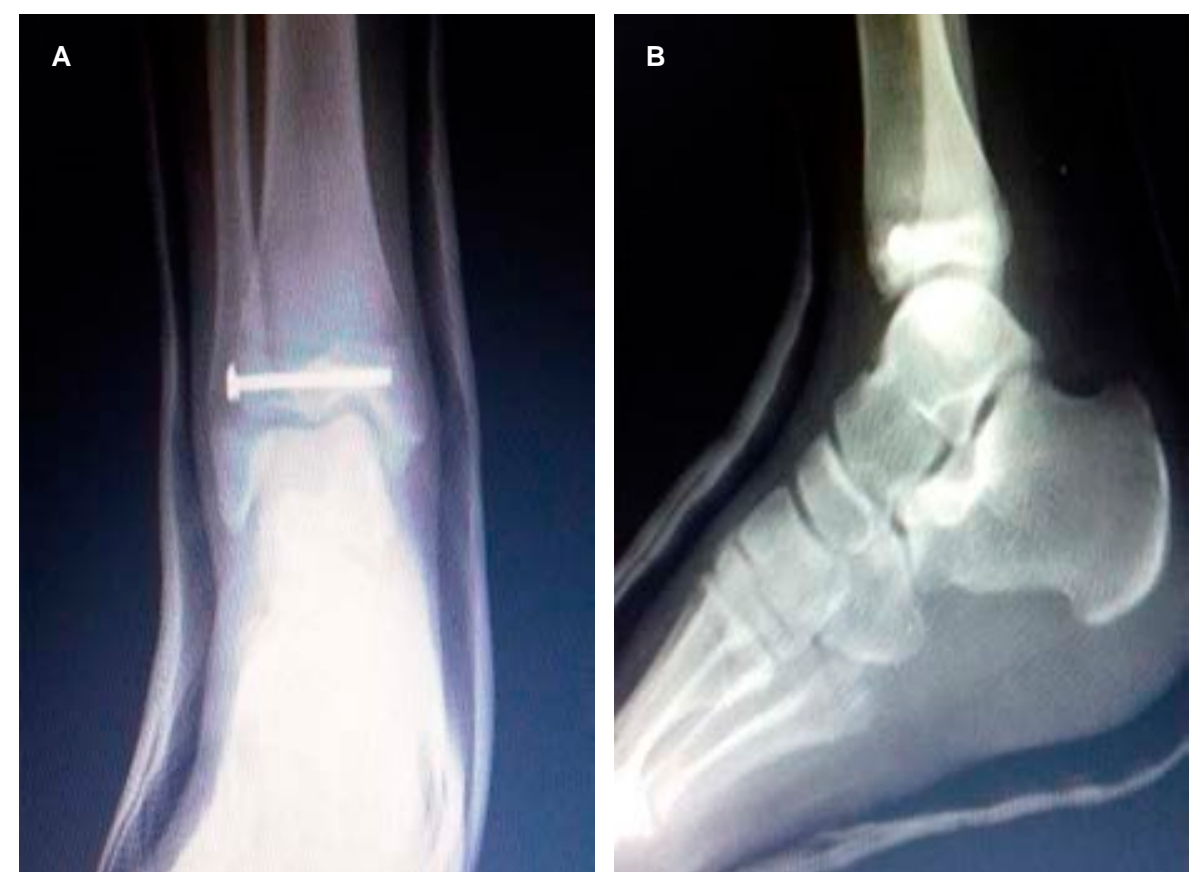

edad en la que ocurren las fracturas de Tillaux en adolescentes, generalmente no es motivo de preocupación que el tornillo cruce o no el centro de crecimiento, ya que éste no aportará crecimiento significativo a futuro. ${ }^{6}$

\section{CONCLUSIÓN}

La fractura de Tillaux es una lesión poco frecuente, por lo cual las imágenes radiológicas tienen un rol fundamental para orientar al clínico en su diagnóstico así como la realización de tomografía computarizada para una mejor caracterización de la lesión, mejor planificación quirúrgica y tratamiento adecuado.

Pese a la complejidad de esta fractura e incluso al compromiso articular, la mayoría de los pacientes tienen buena evolución si el diagnóstico es oportuno y el tratamiento es adecuado.

Debido a la inestabilidad que causa en el tobillo, su tratamiento quirúrgico es indispensable para así evitar la osteoartritis temprana.
Tanto el método tradicional abierto de fijación como el artroscópico tienen más de $85 \%$ de resultados satisfactorios.

\section{REFERENCIAS}

1. Mansur GH, Coelho LT, Barbosa GC, Moreira de Castro JI, Ramos M. Fractura de Tillaux en adultos en asociación con las fracturas Volkmann y Maisonneuve. Reporte de un caso. Rev Col Or Tra. 2019; 33 (3-4): 123-127.

2. Duchesneau S, Fallat LM. The tillaux fracture. J Foot Ankle Surg. 1996; 35 (2): 127-133.

3. Torrent GJ, Castillón BP, Anglès CF. Fractura de Tillaux del adulto: a propósito de un caso. Rev del Pie y Tobillo. 2012; 26 (2): 43-46.

4. Feng SM, Sun QQ, Wang AG, Li CK. "All-inside" arthroscopic treatment of Tillaux-Chaput fractures: clinical experience and outcomes analysis. J Foot Ankle Surg. 2018; 57 (1): 56-59.

5. Jiang L, Wu J, Li M, Liu X, Luo C, Qu X. Cannulated screw and Kirschner fixation for the treatment of medial and lateral malleolar epiphyseal fractures in children: a retrospective study of 36 cases. J Orthop Surg Res. 2019; 14 (1): 254.

6. Cuevas AC. Lesiones fisiarias de la tibia distal. Ortho-tips. 2009; 5 (3): 279-285. 